\title{
Transcatheter aortic valve replacement (TAVR): expanding indications to low-risk patients
}

\author{
Hector Cubero-Gallego ${ }^{1,2}$, Christian Dam ${ }^{3}$, Juan Meca $^{1}$, Pablo Avanzas ${ }^{1,2,4}$ \\ ${ }^{1}$ Heart Area, Hospital Universitario Central de Asturias, Oviedo, Spain; ${ }^{2}$ Instituto de Investigación Sanitaria del Principado de Asturias, Oviedo, \\ Spain; ${ }^{3}$ Department of Cardiac Surgery, Hospital Mexico, San Jose, La Uruca, Costa Rica; ${ }^{4}$ Universidad de Oviedo, Oviedo, Spain \\ Contributions: (I) Conception and design: H Cubero-Gallego, P Avanzas; (II) Administrative support: None; (III) Provision of study materials or \\ patients: None; (IV) Collection and assembly of data: H Cubero-Gallego, P Avanzas; (V) Data analysis and interpretation: H Cubero-Gallego, P \\ Avanzas; (VI) Manuscript writing: All authors; (VII) Final approval of manuscript: All authors. \\ Correspondence to: Pablo Avanzas, MD, PhD, FESC. Heart Area, Hospital Universitario Central de Asturias, Oviedo, Spain. \\ Email: avanzas@secardiologia.es; avanzaspablo@uniovi.es; avanzas@gmail.com.
}

\begin{abstract}
Aortic stenosis (AS) is the most common cardiac valve disease in developed countries. Transcatheter aortic valve replacement (TAVR) for the treatment of severe symptomatic AS is an accepted therapy option for elderly patients with symptomatic severe AS. Nowadays, TAVR has revolutionized the treatment of AS with an exponential growth worldwide. Both the development of new generation valves and the experience of the operating teams have contributed significantly to decrease the complications rate after TAVR. Several randomized trials have reported similar short- and mid-term results, and even better than surgical aortic valve replacement (SAVR) in patients with high- or intermediate-risk. In addition, two comparison trials in low-risk patients have reported promising results. Therefore, in the future TAVR indications will expand, treating younger and younger patients, with less comorbidities and lower risk. However, the long-term durability of percutaneous prostheses is a matter of debate. The aim of this manuscript is to review available data that support to treat AS in low-risk patients and provide our perspective on the topic.
\end{abstract}

Keywords: Aortic stenosis (AS); transcatheter aortic valve replacement (TAVR); surgical aortic calva replacement; low surgical risk

Submitted Feb 27, 2020. Accepted for publication Mar 11, 2020.

doi: $10.21037 / \mathrm{atm} .2020 .03 .155$

View this article at: http://dx.doi.org/10.21037/atm.2020.03.155

\section{Introduction}

Aortic stenosis (AS) is the most common cardiac valve disease in developed countries. Its prevalence increases with advanced age to reach $9.8 \%$ between $80-89$ years (1). Transcatheter aortic valve replacement (TAVR) started in 2002 as a therapy for high-risk patients with severe AS and no other options (2). The procedure is an accepted therapy option for elderly patients with symptomatic severe AS. Nowadays, this new technology has revolutionized the treatment of AS with an exponential growth worldwide. Development of new generation valves and the experience of the operating teams have definitely contributed to decrease the complications rate during TAVR (3).
Complication of the vascular access is one of the most feared; its rate has been reduced with the rigorous selection of the patient, the development of increasingly small-size arterial sheaths, as well as the design of new vascular closure devices (4-6).

Several randomized trials reported similar shortand mid-term results even better than surgical aortic valve replacement (SAVR) in patients with high (7-9) or intermediate surgical risk (10-12). In addition, two comparison trials in low-risk patients have reported promising results $(13,14)$. Thus, it is expected future TAVR indications to expand, treating younger and younger patients, with less comorbidities and lower surgical risk 
(13-15). For these reasons, TAVR programs are developing a minimalist approach to simplify the procedure, with the objectives to reduce complication rates, optimization of procedure time, recovery facilitation and earlier mobilization of the patient, as well as the achievement of a shorter hospital stay, with the decrease of healthcare resource consumption and the reduction of the waiting lists $(16,17)$. However, the long-term durability of percutaneous prostheses is still controversial (18).

The aim of this paper is to review the therapy options to treat AS in low-risk patients and provide our perspective on the topic.

\section{TAVR in low-risk patients}

Low-risk patients with severe AS represent approximately the $80 \%$ of the total of patients with severe AS undergoing SAVR (19). Nowadays, there is a trend to propose TAVR to lower age and risk patients with severe AS (12). The development of new generation valves and the experience of the operators have contributed significantly to decrease the complications rate after TAVR (3-6). Despite recent promising results after TAVR, it should be noted that SAVR outcomes have also improved with a lower mortality than predicted in intermediate-risk patients and comparable to predicted in low-risk patients. However, the median hospital stay after TVAR is 2 days compared to 8 days after SAVR (19).

The NOTION trial (15) is a randomized trial, which compared TAVR vs. SAVR in an all-comers patient cohort; where 280 patients with severe AS with lowand intermediate-risk were randomized to receive a selfexpanding TAVR vs. SAVR. Most patients (81.8\%) were considered at low surgical risk. The mean STS score was $3 \%$. No significant differences were observed between the two groups considering the composite endpoint of death form any cause, stroke or myocardial infarction after 1 year. Patients who underwent TAVR showed larger improvements in effective valvular orifice area, higher degree of aortic valve regurgitation; they needed more frequently a pacemaker (PM) implantation and presented worse New York Heart Association functional class at 1 year. Patients who underwent SAVR showed more major or life-threatening bleeding, cardiogenic shock, acute kidney injury and new-onset of atrial fibrillation (15).

Waksman et al. (20), conducted a non-randomised study in low-risk patients with symptomatic severe AS, which included 200 patients undergoing TAVR whose results were compared with an inverse probability weightingadjusted control cohort of 719 patients who underwent SAVR using the STS database. At 30 days, there was 0 allcause mortality in the TVAR group compared to $1.7 \%$ in the SAVR group. There was 0 in-hospital stroke rate in the TVAR group vs. $0.6 \%$ stroke in the SAVR group. Permanent PM implantation rates were similar between groups (20). In a number of studies, the transfemoral access and the minimalist approach, which includes conscious sedation, valve implantation without pre-dilation, overstimulation with intravenous PM and the use of radial access as a contralateral approach are all variables associated with the acceleration of patient recovery and ambulation $(16,21,22)$.

Recently, two contemporary trials in low-risk patients with severe AS have been reported $(13,14)$. The PARTNER 3 trial (13), randomized 1,000 patients at low 30-day mortality risk (mean STS score was $1.9 \%$ and the mean age was 73 years) to TVAR with the balloon-expandable Sapien 3 prosthesis or SAVR. The assigned procedure was performed in 950 patients (496 in the TVAR group and 454 in the SAVR group). The primary combined endpoint at 1 year (all-cause mortality, stroke, or re-hospitalization) was $8.5 \%$ with TVAR and $15.1 \%$ with SAVR $(\mathrm{P}<0.001)$. The combined endpoint of death and disabling stroke at 1 year was $1 \%$ with TVAR and $2.9 \%$ with SAVR. Hospital stay was shorter with TVAR than with surgery ( $3 v s .7$ days, $\mathrm{P}<0.001)$ and quality of life improved more quickly. Both groups presented similar PM implantation rates, although TVAR was associated with more-frequent new left bundlebranch block [24\% vs. $8 \%$, hazard ratio (HR) 3.43; $95 \%$ confidence interval (CI): $2.3-5.1]$ and mild paravalvular regurgitation (29\% vs. $2 \%)$.

The Evolut Low trial (14) is a randomized trial that included 1,468 patients to any of three self-expanding TVAR prostheses or SAVR (mean age was 74 years and STS score was $1.9 \%$ ). In a prespecified 1-year interim analysis of 784 patients, TVAR and SAVR were estimated to have comparable rates of death or disabling stroke $(2.9 \%$ and $4.6 \%$, respectively). At 30 days, both groups presented similar rates of death $(0.5 \%$ and $1.3 \%)$ and disabling stroke $(0.5 \%$ and $1.7 \%)$. However, TVAR was associated with a higher 30 -day rate of PM implantation $(17.4 \%$ vs. $6.1 \%)$ and moderate/severe paravalvular aortic regurgitation $(3.5 \%$ vs. $0.5 \%)$.

In summary, both trials in patients at low-risk provide data for an early safety, a shorter hospital stay, faster recovery and ambulation, and less re-hospitalizations with 
TAVR in comparison to SAVR. For that reasons, patients who are considered for the treatment of AS undergoing aortic valve replacement with a bioprosthesis should be informed about the two options (TAVR $v s$. SAVR) to get a correct shared decision-making.

Moreover, the randomized NOTION 2 trial (23) is currently enrolling younger patients ( $<75$ years old) with severe AS and low-risk with a Society of Thoracic Surgeons (STS) score $<4 \%$ to be randomized to transfemoral TAVR vs. SAVR. Any CE mark-approved valve is allowed. The primary end-point at 1 year is the composite of all-cause mortality, myocardial infarction and stroke. Finally, the DEDICATE trial (24), will include 1,600 patients with severe AS and low- to intermediate-risk to compare TAVR vs. SAVR in order to assess if TAVR is non-inferior to SAVR regarding short- and long-term mortality.

\section{TAVR in low-risk patients: challenges}

\section{PM implantation}

The incidence of atrioventricular conduction disorders after TAVR is highly variable, ranging from $10 \%$ to $30 \%$ depending on the type of valve implanted (25). The current evidence indicates that both the development of atrioventricular conduction disturbances and the need for definitive PM implantation after TAVR are influenced by anatomical, electrical, type of implanted prosthetic valve and periprocedural factors (26). For the first generation of valves, the PM implantation rate for CoreValve ${ }^{\circledR}$ ranged from $16.3 \%$ in the Italian Registry to $37.7 \%$ in the CHOICE trial (27). For the SAPIEN ${ }^{\circledR}$ valve, the PM implantation rate varied from $2.3 \%$ in the PARTNER EU trial to $17.3 \%$ in the CHOICE trial.

For the new generation of valves, the PM implantation rate after TAVR is highly variable and is influenced by anatomical electrical factors and periprocedural factors (28). According to a meta-analysis of 40 studies (26), for the SAPIEN $^{\circledR} 3$ valve the rate of PM implantation ranged from $4 \%$ to $24 \%$; for the Lotus ${ }^{\circledR}$ valve from $27.9 \%$ to $36.1 \%$ and for the Direct Flow ${ }^{\circledR}$ valve the rate was $17 \%$. According to different series, the rate of PM implantation for the CoreValve Evolut $\mathrm{R}^{\circledR}$ was $26.7 \%$ (11), for the Portico ${ }^{\circledR}$ valve was $13.5 \%$; for JenaValve ${ }^{\circledR} 14.4 \%$; and for ACURATE ${ }^{\circledR}$ the rate varied from $2.3 \%$ to $10.2 \%$.

In the study conducted by Jørgensen et al. (29), 1,190 patients treated with TVAR were included. TVAR patients with new onset of left-bundle-branch block had an increased risk for all causes of early mortality compared with patients who did not have atrioventricular conduction disturbances; the risk of hospitalization for heart failure was increased, as well as all causes of late mortality.

In the NOTION trial (15), the rate of PM implantation was five times higher in the TAVR group compared to the SAVR group ( $41.8 \%$ vs. $8.4 \%)$. At 5 years, all-cause mortality was $38.2 \%$ in the group with PM implantation after procedure vs. $21.7 \%$ in the group that did not need PM implantation. In the Evolut Low Risk trial (14), at 30day follow-up, the PM implantation in the TVAR group was $17.4 \%$ vs. $6.1 \%$ in the SAVR group (difference, 11.3 percentage points; credible interval for the difference, 8 to 14.7). In the PARTNER 3 trial (13), there were no significant differences between TAVR vs. SAVR regarding the new PM implantation at 30 days.

With new-generation TAVR devices, the rates of success, need of second valve implantation, the presence of paravalvular leak and the conversion to SAVR have been reduced. However, the PM implantation rates continues being high (26). In a study of 1,263 patients undergoing TAVR, the new PM implantation was associated with greater morbidity and mortality at long-term followup (30). Main complications after PM implantations are infection, endocarditis and left ventricular dyssynchrony or dysfunction. In addition, the new PM implantation is associated with poorer evolution of left ventricular ejection fraction and it is considered as an independent predictor of lower ejection fraction at 1-year follow-up (31).

\section{Vascular complications}

These complications could lead to bleeding and/or ischaemic complications. New delivery valve systems and smaller sheath diameters are aimed to reduce vascular bleeding complications. However, a recent meta-analysis of randomized trials, which compare TAVR $v s$. SAVR in low-risk patients, showed that TAVR was associated with increased risk for intermediate-term mortality compared to SAVR [17.2\% vs. $12.7 \%$; relative risk (RR): 1.45 , 95\% CI: 1.11-1.89, $\mathrm{P}=0.006]$. Nevertheless, TAVR patients showed less acute kidney injury and bleeding complications, but higher vascular complications and PM implantation rates (32).

In most centers, percutaneous closure of the vascular access of TAVR has become a routine procedure. Percutaneous closure is a much less invasive technique than surgical closure and allows shortening patient's hospital stay by promoting early mobilization and recovery (33). 
The first percutaneous closure device used was the Prostar ${ }^{\circledR}$ closure, later came the Proglide ${ }^{\circledR}$ with a pre-closure system that led to technical simplification and lower costs. The closure of vascular access using two Proglide ${ }^{\circledR}$ devices carries a lower risk of vascular complications compared to closure with $\operatorname{Prostar}^{\circledR}$ (34). The collagen closure device MANTA $^{\circledR}$ is now available with similar results to suturebased closure devices (35).

Percutaneous vascular access technique must be rigorous to limit potential complications in the access area. The puncture site in the common femoral artery should preferably be selected by computed tomography scan before the procedure. During the procedure, the femoral puncture should be guided by ultrasound or angiography, thus reducing complications (17). Notably, most vascular complications could be treated percutaneously with adequate experience of the operating team. This point is essential to simplify the TVAR procedure by facilitating earlier recovery of the patient.

\section{Paravalvular leak}

The NOTION trial (15) showed that TAVR groups showed a rate of $15.7 \%$ of moderate or moderate-to-severe aortic regurgitation; whereas SAVR group showed a rate of $0.9 \%$, persisting at 5 -year follow-up. It is widely known that moderate and severe aortic regurgitation is associated with increased mortality; however, the impact of mild paravalvular leakage on outcomes remains uncertain. The PARTNER 2 trial (10) showed that moderate and severe aortic regurgitation was associated with increased late mortality. The PARTNER 3 trial (13) showed similar rates of moderate or severe paravalvular regurgitation in both groups (TAVR and SAVR).

Technological advances in transcatheter prostheses designs have decreased the differences between TAVR and SAVR regarding the rate of moderate-to-severe aortic regurgitation. Nevertheless, specific anatomical factors, such as bulky eccentric or asymmetric calcifications of the annulus and the left ventricular outflow tract, bicuspid aortic valves and non-circular annulus could lead to reduced aortic regurgitation with surgical treatment.

\section{Prostheses thrombosis}

Chakravarty et al. (36), conducted an observational study, where subclinical leaflet thrombosis was detected on computed tomography, as leaflet thickening or reduced leaflet motion, between $10-15 \%$ of TAVR patients and in $4 \%$ of SAVR patients. Despite that subclinical leaflet thrombosis may improve with anticoagulation, this fact remains uncertain, so that several studies are actually being conducted in order to identify the adequate antithrombotic treatment after TAVR.

\section{Severe bicuspid aortic valve stenosis}

Bicuspid aortic valve is the most common congenital valve disease and is associated with accelerated valve degeneration and concomitant aortic disease (37). There is lack of data on TAVR in bicuspid aortic valve disease. The use of TAVR in a bicuspid aortic valve may result in uneven prosthetic valve expansion and suboptimal function. Bicuspid valves usually present a higher degree of root calcification than the tricuspid aortic valve, increasing the risk of complications (38). In patients with bicuspid aortic valves treated with the first-generation of TVAR, paravalvular leakage grade $\geq 2$ was present in the $28.4 \%$ of patients, requiring the $3.6 \%$ of patients another valve (39). Last valve generation, with a sealing skirt, is associated an improvement of results. Procedural complication rates in patients with severe AS were similar when comparing bicuspid and tricuspid aortic valves (40). Compared with tricuspid aortic valves, the annulus in a bicuspid aortic valve tends to be more elliptical and has more annular calcification with irregular distribution that can affect prosthesis expansion and may increase the risk of paravalvular leakage (41). Notably, concomitant aortopathy; such as dilated ascending aorta, aneurysm or coarctation, which can be associated to this pathology, definitely requires surgical treatment.

\section{Prosthetic valve endocarditis}

Prosthetic valve endocarditis after TAVR is challenging to diagnose. Its incidence is similar to the rates after SAVR: between $0.3 \%$ and $1.2 \%$ per patient-year. Nevertheless, there is a higher incidence, up to $3.4 \%$ per patient-year reported in some series, what may be related to the presence of residual paravalvular leaks and patient comorbidities (42).

\section{Prostheses durability}

The long-term TAVR durability remains uncertain. Prostheses valve durability depends on several factors as age at implantation (43). Most patients in contemporary trials that underwent TAVR were elderly and high-risk patients 
with a life expectancy inferior to the predicted durability of a biological prosthesis. Lastly, there is a trend to standardize definitions of structural deterioration and valve failure when assessing long-term durability of transcatheter and surgical aortic bioprosthetic valves (44). Nevertheless, there are no available data on TAVR durability in younger patients, in whom it is well known that the durability of surgical bioprosthesis is reduced (45).

\section{Conclusions}

Recent available data on TAVR at low-risk patients may lead to this procedure to be quickly approved as an alternative to SAVR for patients that will prefer a less-invasive approach. For that reasons, the role of the heart team will be relevant in the decision-making process when referring a patient for aortic valve replacement. However, despite the exponential growth of TAVR, SAVR should remain as the standard treatment for severe AS in patients with active endocarditis, young patients, which would benefit more from a mechanical prosthesis due to the lack of data on the TAVR durability, and patients with indication of coronary artery bypass grafting or other concomitant procedures, like additional valve or aortic surgery.

\section{Acknowledgments}

Funding: None.

\section{Footnote}

Provenance and Peer Review: This article was commissioned by the Guest Editor (Daniel Hernandez-Vaquero) for the series "Structural Heart Disease: The Revolution" published in Annals of Translational Medicine. The article was sent for external peer review organized by the Guest Editor and the editorial office.

Conflicts of Interest: All authors have completed the ICMJE uniform disclosure form (available at http://dx.doi. org/10.21037/atm.2020.03.155). The series "Structural Heart Disease: The Revolution" was commissioned by the editorial office without any funding or sponsorship. The authors have no other conflicts of interest to declare.

Ethical Statement: The authors are accountable for all aspects of the work in ensuring that questions related to the accuracy or integrity of any part of the work are appropriately investigated and resolved.

Open Access Statement: This is an Open Access article distributed in accordance with the Creative Commons Attribution-NonCommercial-NoDerivs 4.0 International License (CC BY-NC-ND 4.0), which permits the noncommercial replication and distribution of the article with the strict proviso that no changes or edits are made and the original work is properly cited (including links to both the formal publication through the relevant DOI and the license). See: https://creativecommons.org/licenses/by-nc-nd/4.0/.

\section{References}

1. Eveborn GW, Schirmer H, Heggelund G, et al. The evolving epidemiology of valvular aortic stenosis. the Tromsøstudy. Heart 2013;99:396.

2. Cribier A, Eltchaninoff H, Bash A, et al. Percutaneous transcatheter implantation of an aortic valve prosthesis for calcific aortic stenosis: first human case description. Circulation 2002;106:3006-8.

3. Baumgartner H, Falk V, Bax JJ, et al. ESC Scientific Document Group, ESC/EACTS Guidelines for the management of valvular heart disease. Eur Heart J 2017;38:2739-91.

4. Auffret V, Lefèvre T, Van Belle E, et al. Temporal trends in transcatheter aortic valve replacement in France: FRANCE 2 to FRANCE TAVI. JACC 2017;70:42-55.

5. Durand E, Borz B, Godin M, et al. Transfemoral aortic valve replacement with the Edwards SAPIEN and Edwards SAPIEN XT prosthesis using exclusively local anesthesia and fluoroscopic guidance: feasibility and 30day outcomes. JACC Cardiovasc Interv 2012;5:461-7.

6. Kodali S, Thourani VH, White J, et al. Early clinical and echocardiographic outcomes after SAPIEN 3 transcatheter aortic valve replacement in inoperable, high-risk and intermediate-risk patients with aortic stenosis. Eur Heart J 2016;37:2252-62.

7. Gleason TG, Reardon MJ, Popma JJ, et al. CoreValve U.S. Pivotal High Risk Trial Clinical Investigators. 5-Year outcomes of self-expanding transcatheter versus surgical aortic valve replacement in high-risk patients. J AmColl Cardiol 2018;72:2687-96.

8. Smith CR, Leon MB, Mack MJ, et al. PARTNER Trial Investigators. Transcatheter versus surgical aorticvalve replacement in high-risk patients. N Engl J Med 2011;364:2187-98.

9. Mack MJ, Leon MB, Smith CR, et al. PARTNER 1 trial 
investigators. 5-Year outcomes of transcatheter aortic valve replacement or surgical aortic valve replacement for high surgical risk patients with aortic stenosis (PARTNER 1): a randomised controlled trial. Lancet 2015;385:2477-84.

10. Leon MB, Smith CR, Mack MJ, et al. PARTNER 2 Investigators. Transcatheter or surgical aortic-valve replacement in intermediate-risk patients. $\mathrm{N}$ Engl J Med 2016;374:1609-20.

11. Reardon MJ, Van Mieghem NM, Popma JJ, et al. SURTAVI Investigators. Surgical or transcatheter aorticvalve replacement in intermediate-risk patients. N Engl J Med 2017;376:1321-31.

12. Thourani VH, Kodali S, Makkar RR, et al. Transcatheter aortic valve replacement versus surgical valve replacement in intermediate-risk patients: a propensity score analysis. Lancet 2016;387:2218-25.

13. Mack MJ, Leon MB, Thourani VH, et al. Transcatheter Aortic-Valve Replacement with a Balloon-Expandable Valve in Low-Risk Patients. N Engl J Med 2019;380:1695-705.

14. Popma JJ, Deeb GM, Yakubov SJ, et al. Transcatheter Aortic-Valve Replacement with a Self-Expanding Valve in Low-Risk Patients. N Engl J Med 2019;380:1706-15.

15. Thyregod HG, Steinbrüchel DA, Ihlemann N, et al. Transcatheter Versus Surgical Aortic Valve Replacement in Patients with Severe Aortic Valve Stenosis: 1-Year Results From the All-Comers NOTION Randomized Clinical Trial. J Am Coll Cardiol 2015;65:2184-94.

16. Babaliaros V, Devireddy C, Lerakis S, et al. Comparison of transfemoral transcatheter aortic valve replacement performed in the catheterization laboratory (minimalist approach) versus hybrid operating room (standard approach): outcomes and cost analysis. JACC Cardiovasc Interv 2014;7:898-904.

17. Sawaya FJ, Lefèvre T, Spaziano M, et al. Transfemoral transcatheter aortic valve implantation: how minimalistic can we become? J Interv Cardiol 2016;29:628-31.

18. Rosato S, Santini F, Barbanti M, et al. OBSERVANT Research Group. Transcatheter aortic valve implantation compared with surgical aortic valve replacement in lowrisk patients. Circ Cardiovasc Interv 2016;9:e003326.

19. Thourani VH, Suri RM, Gunter RL, et al. Contemporary real-world outcomes of surgical aortic valve replacement in 141,905 low-risk, intermediate-risk, and high-risk patients. Ann Thorac Surg 2015;99:55-61.

20. Waksman R, Rogers T, Torguson R, et al. Transcatheter Aortic Valve Replacement in Low-Risk Patients with Symptomatic Severe Aortic Stenosis. J Am Coll Cardiol
2018;72:2095-105.

21. Allende R, Urena M, Cordoba JG, et al. Impact of the use of transradial versus transfemoral approach as secondary access in transcatheter aortic valve implantation procedures. Am J Cardiol 2014;114:1729-34.

22. Eskandari M, Aldalati O, Dworakowski R, et al. Comparison of general anaesthesia and non-general anaesthesia approach in transfemoral transcatheter aortic valve implantation. Heart 2018;104:1621-8.

23. US National Library of Medicine. ClinicalTrials.gov 2018. Available online: https://ClinicalTrials.gov/show/ NCT02825134

24. US National Library of Medicine. ClinicalTrials.gov 2019. Available online: https://ClinicalTrials.gov/show/ NCT03112980

25. Auffret V, Puri R, Urena M, et al. Conduction disturbances after transcatheter aortic valve replacement: current status and future perspectives. Circulation 2017;136:1049-69.

26. van Rosendael PJ, Delgado V, Bax JJ. Pacemaker implantation rate after transcatheter aortic valve implantation with early and new-generation devices: a systematic review. Eur Heart J 2018;39:2003-13.

27. Abdel-Wahab M, Mehilli J, Frerker C, et al. Comparison of balloon-expandable vs self-expandable valves in patients undergoing transcatheter aortic valve replacement: the $\mathrm{CHOICE}$ randomized clinical trial. JAMA 2014;311:1503-14.

28. Fadahunsi OO, Olowoyeye A, Ukaigwe A, et al. Incidence, predictors, and outcomes of permanent pacemaker implantation following transcatheter aortic valve replacement: analysis from the U.S. Society of Thoracic Surgeons/American College of Cardiology TV'T Registry. JACC Cardiovasc Interv 2016;9:2189-99.

29. Jørgensen TH, De Backer O, Gerds TA, et al. Mortality and Heart Failure Hospitalization in Patients With Conduction Abnormalities After Transcatheter Aortic Valve Replacement. JACC Cardiovasc Interv 2019;12:52-61.

30. Aljabbary T, Qiu F, Masih S, et al. Association of clinical and economic outcomes with permanent pacemaker implantation after transcatheter aortic valve replacement. JAMA Netw Open 2018;1:e180088.

31. Urena M, Webb JG, Tamburino C, et al. Permanent pacemaker implantation after transcatheter aortic valve implantation: impact on late clinical outcomes and left ventricular function. Circulation 2014;129:1233-43.

32. Witberg G, Lador A, Yahav D, et al. Transcatheter versus surgical aortic valve replacement in patients at low surgical risk: A meta-analysis of randomized trials and propensity 
score matched observational studies. Catheter Cardiovasc Interv 2018;92:408-16.

33. Kadakia MB, Herrmann HC, Desai ND, et al. Factors associated with vascular complications in patients undergoing balloon-expandable transfemoral transcatheter aortic valve replacement via open versus percutaneous approaches. Circ Cardiovasc Interv 2014;7:570-6.

34. Mehilli J, Jochheim D, Abdel-Wahab M, et al. One-year outcomes with two suture-mediated closure devices to achieve access-site haemostasis following transfemoral transcatheter aortic valve implantation. EuroIntervention 2016;12:1298-304.

35. De Palma R, Settergren M, Rück A, et al. Impact of percutaneous femoral arteriotomy closure using the MANTATM device on vascular and bleeding complications after transcatheter aortic valve replacement. Catheter Cardiovasc Interv 2018;92:954-61.

36. Chakravarty T, Søndergaard L, Friedman J, et al. Subclinical leaflet thrombosis in surgical and transcatheter bioprosthetic aortic valves: an observational study. Lancet 2017;389:2383-92.

37. Roberts WC, Janning KG, Ko JM, et al. Frequency of congenitally bicuspid aortic valves in patients $\geq 80$ years of age undergoing aortic valve replacement for aortic stenosis (with or without aortic regurgitation) and implications for transcatheter aortic valve implantation. Am J Cardiol 2012;109:1632-6.

38. Zegdi R, Ciobotaru V, Noghin M, et al. Is it reasonable to treat all calcified stenotic aortic valves with a valved stent? Results from a human anatomic study in adults. J Am Coll Cardiol 2008;51:579-84.

39. Mylotte D, Lefevre T, Søndergaard L, et al. Transcatheter

Cite this article as: Cubero-Gallego H, Dam C, Meca J, Avanzas P. Transcatheter aortic valve replacement (TAVR): expanding indications to low-risk patients. Ann Transl Med 2020;8(15):960. doi: 10.21037/atm.2020.03.155 aortic valve replacement in bicuspid aortic valve disease. J Am Coll Cardiol 2014;64:2330-9.

40. Yoon SH, Bleiziffer S, De Backer O, et al. Outcomes in Transcatheter Aortic Valve Replacement for Bicuspid Versus Tricuspid Aortic Valve Stenosis. J Am Coll Cardiol 2017;69:2579-89.

41. Zhao ZG, Jilaihawi H, Feng Y, et al. Transcatheter aortic valve implantation in bicuspid anatomy. Nat Rev Cardiol 2015;12:123-8.

42. Puls M, Eiffert H, Hünlich M, et al. Prosthetic valve endocarditis after transcatheter aortic valve implantation: the incidence in a single-centre cohort and reflections on clinical, echocardiographic and prognostic features. EuroIntervention 2013;8:1407-18.

43. Bourguignon T, Bouquiaux-Stablo AL, Candolfi P, et al. Very long-term outcomes of the Carpentier-Edwards Perimount valve in aortic position. Ann Thorac Surg 2015;99:831-7.

44. Capodanno D, Petronio AS, Prendergast B, et al. Standardized definitions of structural deterioration and valve failure in assessing long-term durability of transcatheter and surgical aortic bioprosthetic valves: a consensus statement from the European Association of Percutaneous Cardiovascular Interventions (EAPCI) endorsed by the European Society of Cardiology (ESC) and the European Association for Cardio-Thoracic Surgery (EACTS). Eur Heart J 2017;38:3382-90.

45. Barbanti M, Costa G, Zappulla P, et al. Incidence of LongTerm Structural Valve Dysfunction and Bioprosthetic Valve Failure After Transcatheter Aortic Valve Replacement. J Am Heart Assoc 2018;7:e08440. 